ges that the amount of institute research will be halved and university research doubled. More institute scientists are teaching (one-third of his Institute's research staff now lecture regularly in universities) and the Solid State Institute's facilities are used by students.

It is also hoped to change graduate training by creating institutions akin to graduate schools to bridge the university institute gap. The University of Debrecen and the nearby Institute of Nuclear Physics led the way with a common unit devoted to providing teaching and research facilities for graduates in nuclear physics (Professor Lovás, the KFKI's Director-General, holds a chair of theoretical physics in the University). Meanwhile, the Institute of Solid State Research, the Eötvos, Medical and Technical Universities in Budapest and universities in Szeged and Tilich have agreed to combine efforts in graduate and postgraduate education and research by forming a loose confederation of the interested facilities and professorial chairs (the last signature of the letter of intent was received last month). Called the Athenaeum, the aim is to start operation in 1992, initially in the fields of material and solid state physics and in quantum electronics. Professor Kroo believes that eventually maybe as many as $300-400$ graduates and postgraduates would be involved so the initiative could become an important element of a restructured physics community.

The Athenaeum hopes that the pooling of resources and adopting a united approach to funding agencies will allow research facilities to be brought to modern standards by improving the existing laboratory infrastructure and equipment and by installing computer links.

Ambitious plans to make a significant impact on a countries education programme naturally call for important funding. Hungary was one of the first countries to submit proposals for restructuring to the European Community's PHARE Programme (with a budget of 800 MECU for $1990 / 1$ with no a priori splitting) which forms the basis of the EC's activities in favour of central Europe. Proposals are made through national offices on the basis of a Directive Plan submitted by each country. The PHARE Committee composed of representatives of the donors (the EC, the USA and Japan) meets every two months to agree proposals, and project implementation varies according to the requirements. Hungary included science and research in its 1990/1 Directive Plan and some of the proposed restructuring required by PHARE has already taken place (increasing student numbers, introducing additional freedom of choice in course selection and the new two-level undergraduate programme).
The Athenaeum initiative clearly represents a significant element in this restructuring by reconfiguring resources, so it is seeking some $1 \mathrm{MECU}$ for infrastructure development and 1-2 KECU for invited students, professors and researchers through a PHARE proposal submitted by the Hungarian Ministry of Industrial Development (MID). Domestic funding sources are also sought (from the Minister of Education and from OTKE, the National Organization for Scientific Research). The MID and OTKE are already heavily involved in supporting science as they, together with direct government funding, cover a major part of the budget of the Academy of Sciences and its Institutes, which are still effectively managed by the Academy, although the trend is for it to "retreat within its noble boundaries" by becoming a purely consultative body.
The Athenaeum will also provide some innovative approaches to tackling the industry - research gap. For instance, Hungarian engineers needed in high technology industries such as microelectronics are thought to lack training in basic subjects so it is planned to offer high level courses in physics-related topics to several tens of engineers from the Technical University and elsewhere after their threeyear basic course.

All in all, there is a will in Hungary to support basic and long-term physics research and to develop the required skills as "science provides the essential background to industry". In the meantime, the urgent need is to reduce bureaucracy, and the great danger is that people may become depressed if the expected miracles do not materialize.

P. G. Boswell

\title{
Extended Shutdown for ILL Neutron Source
}

The Institut von Laue-Langevin in Grenoble with its High Flux Reactor neutron source. Shown in the foreground is the building that is being constructed to house the storage ring of the European Synchrotron Radiation Facility (ESRF).

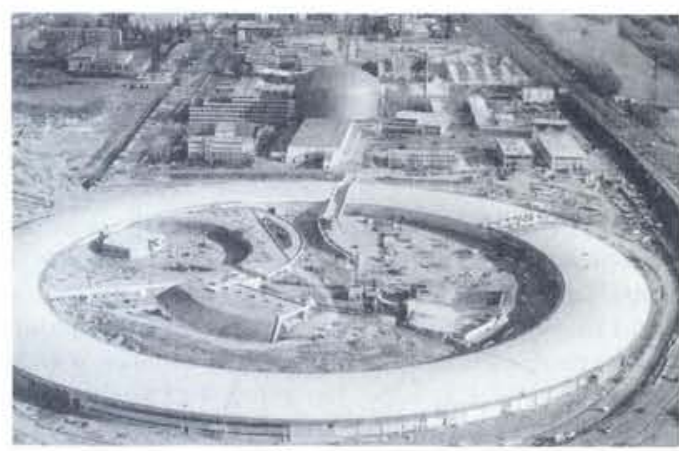

The Institut Laue-Langevin (ILL) in Grenoble, France, has announced that its $55 \mathrm{MW}$ High Flux Reactor neutron source for structure studies would not be restarted as scheduled at the end of a routine inspection that began on 30 March 1991 and would normally have lasted a few days. This was because elongated, radially orientated "traces inhabituelles" (literally, unusual traces) had been observed on the upper surface of the upper baffle of a two-baffle assembly located near the bottom of the reactor vessel. This 2.5 metre diameter, $6 \mathrm{~mm}$ thick aluminium alloy baffle plate has 6000 holes of $9.5 \mathrm{~mm}$ diameter that serve to quieten circulating heavy water coolant which is pumped under pressure into the bottom of the vessel. The traces were found on April 5 during a remote examination by video camera of the interior of the vessel and its components: a detailed on-going inspection has confirmed the observations.

The ILL, whose function is to make available a range of instruments for structure studies to the scientific community, charges its Reactor Division with supplying neutrons. Dr. E. Bauer, the Head, has indicated that the ILL Directors will propose to the ILL Steering Committee, comprising representatives of the four national Associate Members and responsible for establishing the general rules for managing the Institute, that the baffle assembly be replaced. This intervention will take up to about one year to prepare and a similar period to carry out.

Operation of the ILL's reactor is the same as for any other French reactor and is "fully embedded" in the French nuclear safety system reporting to a Minister. The observations were reported immediately to the relevant authority and it is the Minister who will authorize the ILL's proposed intervention plan. Safety procedures had been recently reevaluated in the investigation process which followed the discovery, in early 1990, that the HFR had been operating above its rated power for some time owing to erroneous calibration.

The inevitably extended shutdown will clearly have important consequences for the 1500 users of the ILL's 30 instruments who made 2400 individual visits in 1990 , especially since they had to adjust to the 1990 shutdown which reduced the number of 44 day operating cycles from 6 to 4.5 only a year after the ILL had boosted the annual beam time from roughly 220 hours to 262 hours in 1989 to cope with excess demand. The future of the 99 th beam cycle, that was postponed soon after the traces were observed and had been tentatively scheduled to start on 18 June, is undecided. 